\title{
Surgery of atlantoaxial dislocation by Posterior Decompression Fusion \& Fixation at Lateral Mass Screw of C1 \& Pedicle Screw \& Rod by C2: A Study of 30 Cases
}

\author{
Nath $\mathrm{HD}^{1}$, Barua $\mathrm{KK}^{2}$, Banyea $\mathrm{P}^{3}$, Biswas $\mathrm{PK}^{4}$, Halder $\mathrm{R}^{5}$, Ahsan $\mathrm{A}^{6}$
}

Conflict of interest: There is no conflict of interest relevant to this paper to disclose.

Funding Agency : was not funded by any institute or any group.

Contribution of Authors : Principal Investigator- Dr. Haradhan Deb nath,

Manuscript preparation- Dr. Kanak Kanti Barua

Data collection- Dr. Moinul Islam, Dr. Purusttam Banyea, Pulak Kumar Biswas

Editorial formatting- Dr. Rathin Halder, Dr. Md. Ashik Ahsan

Copyright: @2020bang.BJNS published by BSNS. This article is published under the creative commons CC-BY-NC license. This license permits use distribution (https://creativecommons. orgf/licences/by-nc/4-0/)reproduction in any medium, provided the original work is properly cited and is not used for commercial purposes.

Received: 04/03/2020

Accepted: 05/12/2020

\begin{abstract}
:
Background: Atlantoaxial dislocation $(A A D)$ is a potentially fatal disturbance to the normal occipital-cervical anatomy that affects some populations disproportionately, which may cause permanent neurologic deficits or sagittal deformity if not treated in a timely and appropriate manner.
\end{abstract}

Methods: This was a cross sectional study, which was carried out at the Department of Neurosurgery, Bangabandhu Sheikh Mujib Medical University from July 2010 to June 2017. We have studied 30 patients of atlantoaxial subluxation. After collecting patient admission data a brief history and clinical examinations were done. We have conducted a retrospective analysis of the outcomes of 30 consecutive spinal surgeries performed for AAS patients, by posterior decompression, fusion \& fixation at lateral mass screw of $C 1$ \& pedicle screw \& rod by $C 2$ in all cases. We have compared our findings with a previous study. We also examined the factors related to poor outcomes.

Result: From a surgical method perspective, the patients underwent post decompression, fusion \& fixation at lateral mass screw of $C 1 \&$ pedicle screw $\&$ rod by C2. After surgery, closed follow up was done. The highest age group was 21-40 years 40\%. Most of the sufferer were male $80 \%$. The commonest cause was road traffic accident $26.66 \%$. The commonest clinical finding was quadriparesis $14(46.67 \%)$. The majority of the patients 24(80\%) improved after surgery. In our present study after surgery neurological improvement rate is $83.33 \%$, the rate of SSI was indeed high $10.00 \%$, total death rate was $3.33 \%$, the hardware failure rate was $3.33 \%$ and the reoperation rate reached $6.66 \%$.

Conclusion: The results of this study showed that the C1/2 fixation technique exhibited effectiveness in terms of neurological recovery.

Bang. J Neurosurgery 2021; 10(2): 148-153

\section{Introduction:}

Atlantoaxial dislocation refers to a loss of stability between the atlas and axis (C1-C2), resulting in loss of normal articulation. The atlantoaxial joints can lose stable articulation from traumatic, inflammatory, idiopathic, or congenital abnormalities. ${ }^{1}$ The mechanism of injury typically remains unidentified with several theories proposed in the literature. ${ }^{2}$ Although it occurs in all age groups, atlantoaxial dislocation is most often seen in adolescents.

Atlantoaxial dislocations have been previously studied extensively and reported in the literature with subsequent treatment recommendations published using older, less relevant classification systems. The

1. Dr. Haradhan Deb nath, Professor, Department of Neurosurgery, BSMMU

2. Dr. Kanak Kanti Barua, Honorable Vice Chancellor \& Professor, BSMMU

3. Dr. Purusttam Banyea, Consultant Neurosurgeon, Nepal.

4. Pulak Kumar Biswas, Assistant Registrar, Department of Neurosurgery, SSMC \& MH

5. Dr. Rathin Halder, Chief Resident, Department of Neurosurgery, BSMMU

6. Dr. Md. Ashik Ahsan, Chief Resident, Department of Neurosurgery, BSMMU

Address of Correspondence: Dr. Haradhan Deb nath, Professor, Department of Neurosurgery, BSMMU, Mobile: 01711354120 , Email: dr.haradhan@yahoo.com 
atlantoaxial joint allows complex movements of the cervical spine while providing sufficient mechanical strength to stabilize the head. About $50 \%$ of total cervical spine flexion and extension occurs at the occiput-C1 articulation. ${ }^{2}$

Flexibility is provided by the dens (odontoid process) of $\mathrm{C} 2$ (the axis), which articulates with the $\mathrm{C} 1$ (atlas) and transverse ligaments, accounting for over $50 \%$ of all cervical spine rotation. ${ }^{2}$ To provide this flexibility, the synovial joints at these segments do not have the same osseous and intervertebral disk-related stability mechanisms as the rest of the spinal column, relying more on ligamentous stabilizers. ${ }^{3}$

The region is unique in that the occiput- $\mathrm{C} 1$ articulation and the $\mathrm{C} 1-\mathrm{C} 2$ articulation are the only vertebral segments without intervertebral disks, and the vertebral bodies do not directly bear the load distribution from the occiput. The occipital condyles transfer the load at the articulation with the $\mathrm{C} 1$ lateral masses, which transfers the load onto the $\mathrm{C} 2$ lateral masses. ${ }^{2}$

Atlantoaxial dislocation can be broadly categorized into separate traumatic, congenital, or inflammatory etiologies, although the cause is commonly multifactorial. A purely traumatic atlantoaxial dislocation in the absence of another predisposing risk factor is extremely rare. ${ }^{1} \mathrm{~A}$ literature review by Venkatesan et al in 2012 found only 12 adult case reports.

Traumatic atlantoaxial dislocation is due to forced displacement of the neck resulting in disruption of the transverse ligament. ${ }^{4}$ Certain congenital conditions are associated with craniocervical region abnormalities that predispose these populations to developing atlantoaxial dislocation.

One particularly well-studied condition is Down syndrome. Down syndrome (trisomy 21) is the most common inherited chromosomal disorder. Predisposing sequela include hypermobility and instability caused by ligamentous laxity and osseous abnormalities, ${ }^{1}$ resulting in an increased incidence of atlantoaxial dislocation (15 to $20 \%$ ). Another notable population that is disproportionately affected by atlantoaxial dislocation is chronic rheumatoid arthritis patients, particularly adults.

The atlantoaxial joint is frequently affected in rheumatoid arthritis with studies showing incidence rates ranging from 23 to $86 \%$ of patients with rheumatoid arthritis. The presentation of atlantoaxial dislocation may range from minor axial neck pain to death. Approximately $50 \%$ of patients present with neck pain and/or neck movement restriction, $70 \%$ with weakness and/or numbness, and $90 \%$ with pyramidal signs. ${ }^{7}$

Other preoperative clinical presentations include sphincter disturbances, lower cranial nerve dysfunction, and respiratory distress. Other serious sequelae include myelopathy, respiratory failure, vertebral artery dissection, neurologic compromise, and rarely quadriplegia or death if left untreated. 8,9 The differential diagnosis of atlantoaxial dislocation includes torticollis, atlantoaxial rotary fixation, and odontoid fractures without atlantoaxial dislocation. There are several different approaches to diagnosing atlantoaxial dislocation; however, no consensus exists.

Atlantoaxial dislocation can be defined with radiographic measurements of atlantoaxial joint articulation using the atlantodental interval (ADI). The $A D I$ is a small slit like space between the posterior aspect of the anterior atlas ring and the anterior aspect of the odontoid process. Flexion and extension radiographs of the neck allow for the measurement of the ADI and to determine whether the atlantoaxial joint reduces itself in these positions.

\section{Objectives:}

Atlantoaxial dislocation (AAD) is a potentially fatal disturbance to the normal occipital-cervical anatomy that affects some populations disproportionately, which may cause permanent neurologic deficits or sagittal deformity if not treated in a timely and appropriate manner. The objective of this review is to provide a comprehensive review of the literature to identify timely and effective diagnostic techniques and treatment modalities of AAD.

Result:

Table-I

Distribution of patients by age $(n=30)$

\begin{tabular}{lcc}
\hline Age in years & Number & Percentage \\
\hline $1-20$ & 6 & 20.0 \\
$21-40$ & 12 & 40.0 \\
$41-60$ & 8 & 26.6 \\
$>60$ & 4 & 13.33 \\
\hline
\end{tabular}

Table I shows the highest age groups were $21-40$ years (40\%) 
Table-II

Sex distribution of patients $(n=30)$

\begin{tabular}{lcc}
\hline Age in years & Number & Percentage \\
\hline Male & 18 & 60.0 \\
Female & 12 & 40.0 \\
\hline
\end{tabular}

Table II shows among the patients $18(60 \%)$ were male and $12(40 \%)$ were female.

Table-III

Distribution of patients by occupation $(n=30)$

\begin{tabular}{lcc}
\hline Occupation & Number & Percentage \\
\hline Day laborer & 15 & 50.0 \\
Service holder & 2 & 6.66 \\
Farmer & 8 & 26.66 \\
Professional & 1 & 3.33 \\
House wife & 2 & 6.66 \\
Others & 2 & 6.66 \\
\hline
\end{tabular}

Table III shows the commonest occupational group was day laborer

Table-IV

Distribution of patients by causes of spinal cord compression $(n=30)$

\begin{tabular}{lcc}
\hline Cause & Number & Percentage \\
\hline Road traffic accident & 8 & 26.66 \\
Fall from height & 6 & 20.0 \\
Fall of heavy object on the neck & 4 & 13.33 \\
Rheumatic arthritis & 3 & 10.00 \\
Akkylosis spoondylithis & 2 & 6.66 \\
Chiari malformation & 3 & 10.00 \\
Occipitalization & 2 & 6.66 \\
Infection & 2 & 6.66 \\
\hline
\end{tabular}

Table-V

Distribution of patients by type of clinical significant $(n=30)$

\begin{tabular}{lcc}
\hline Clinical features & Number & Percentage \\
\hline Hempiaresis & 6 & 20.00 \\
Lower cranial palsy & 4 & 13.33 \\
Quadriparesis & 15 & 50.00 \\
Quadriplegia & 5 & 16.6 \\
\hline
\end{tabular}

Table shows that the most of the suffers had quadriparesis (50\%).
Table-VI

Distribution of patients by outcome after surgery

\begin{tabular}{lcc}
\hline $\begin{array}{l}\text { Outcome of patients } \\
\text { after surgery }\end{array}$ & Number & Percentage \\
\hline Partially improved & 10 & 33.33 \\
Completely cured & 15 & 50.0 \\
Same as before & 4 & 13.33 \\
(no improvement) & & \\
Died & 1 & 3.33 \\
Re Operation & 02 & 6.66 \\
\hline
\end{tabular}

Table VI shows $83.33 \%$ of the patients either cured or improved after surgery.

Table-VII

Distribution of the patients by complication after surgery $(n=30)$

\begin{tabular}{lcc}
\hline Complication & Number & Percentage \\
\hline SSI & 3 & 10.00 \\
Screw and rod dislocation & 1 & 3.33 \\
Died & 1 & 3.33 \\
\hline
\end{tabular}

Table shows $10 \%$ of patients had wound infection and $3.33 \%$ of patients had screw and plate dislocation.

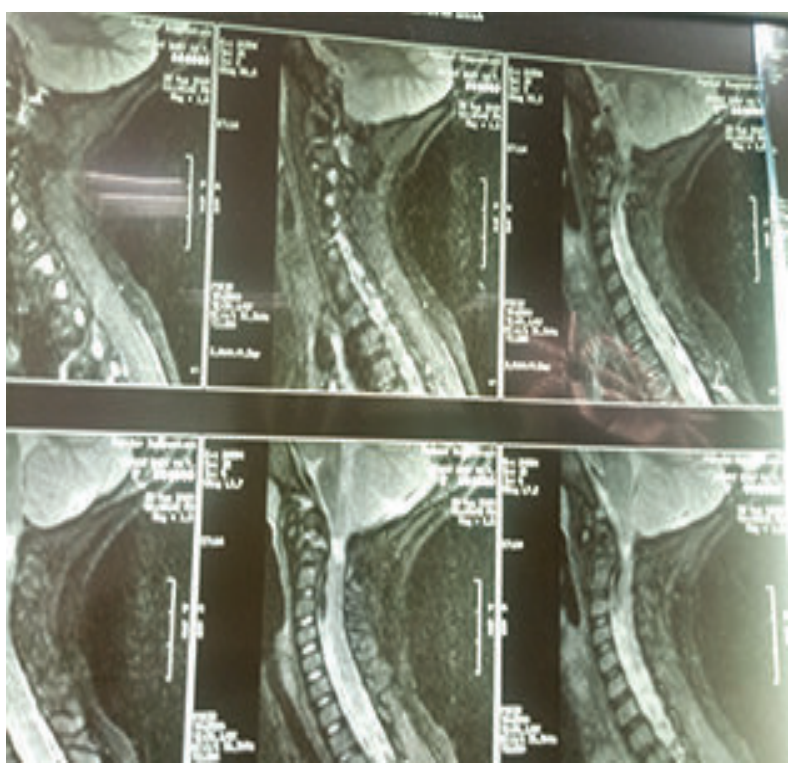

Fig.-1: MRI of cervical spine showed atlantoaxial dislocation with cord compression 


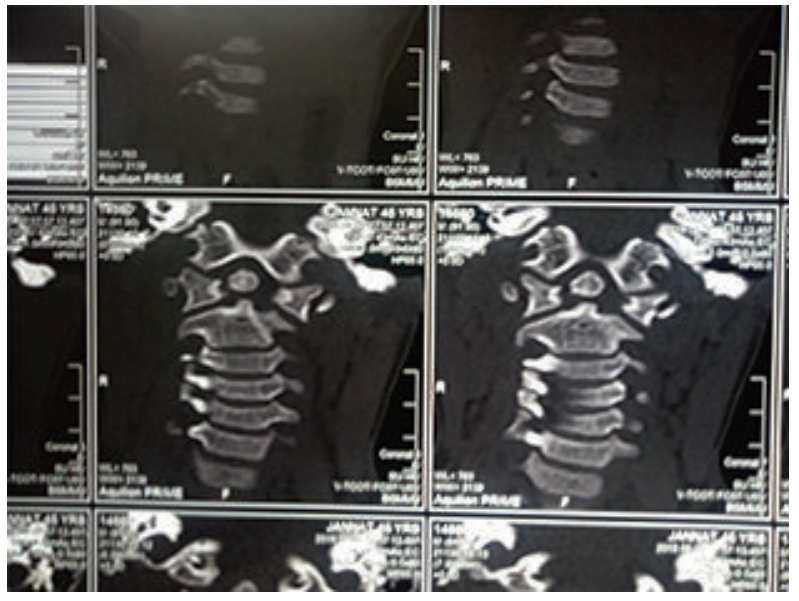

Fig.-2: CT scan upper cervical spine showed fracture odontoid tip

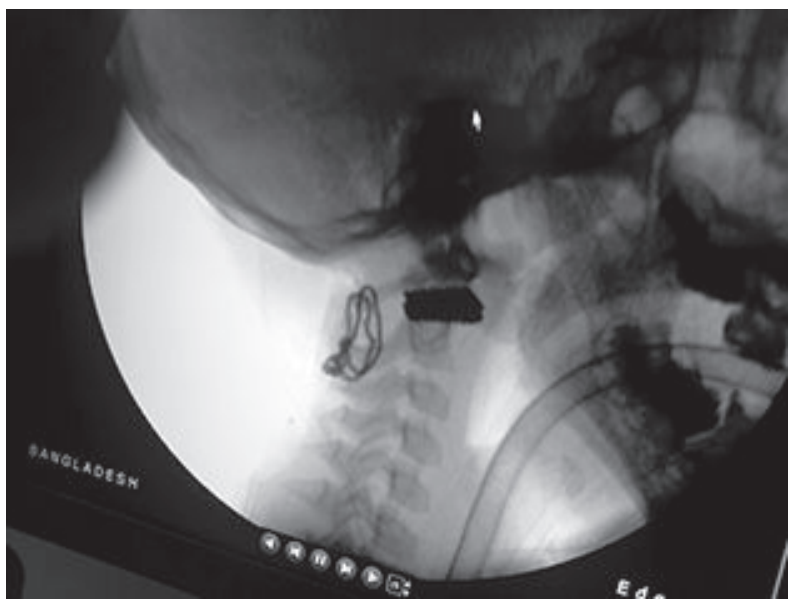

Fig.-3: Showed posterior fusion \& fixation by wiring, case \& autologous bone

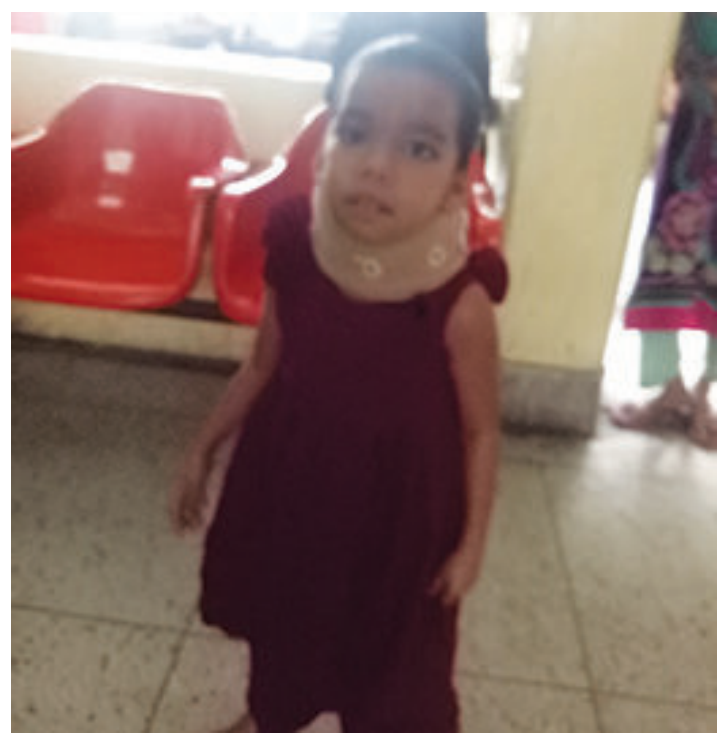

Fig.-4: Postoperative patients

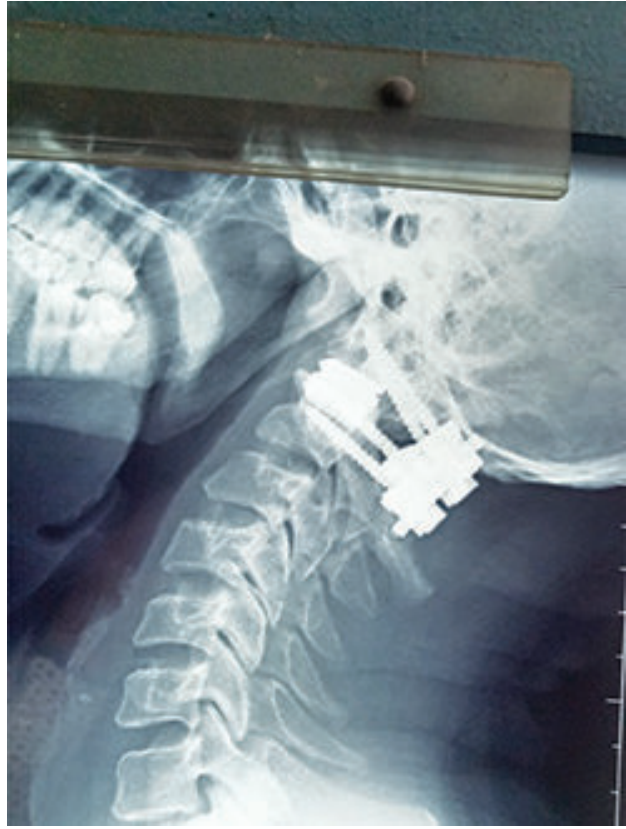

Fig.-5: Postoperative after fixation

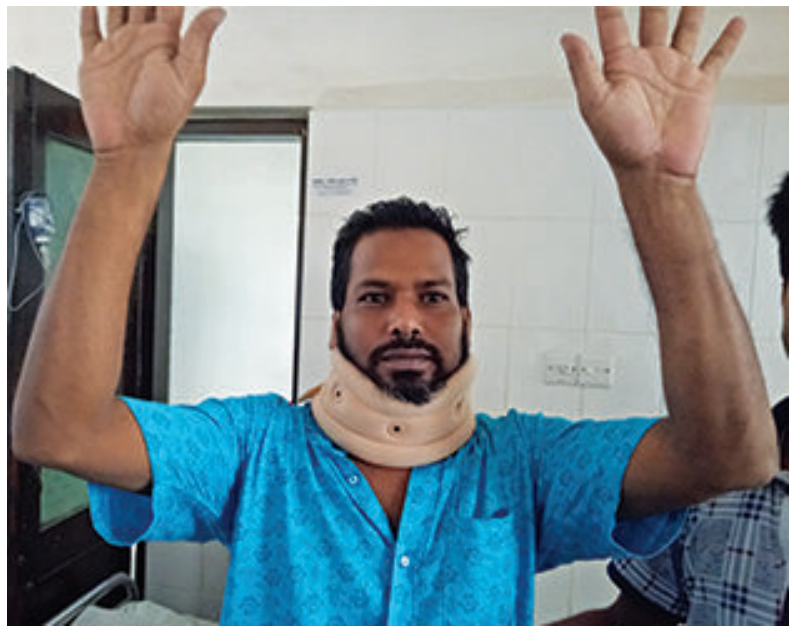

Fig.-6: Postoperative patients

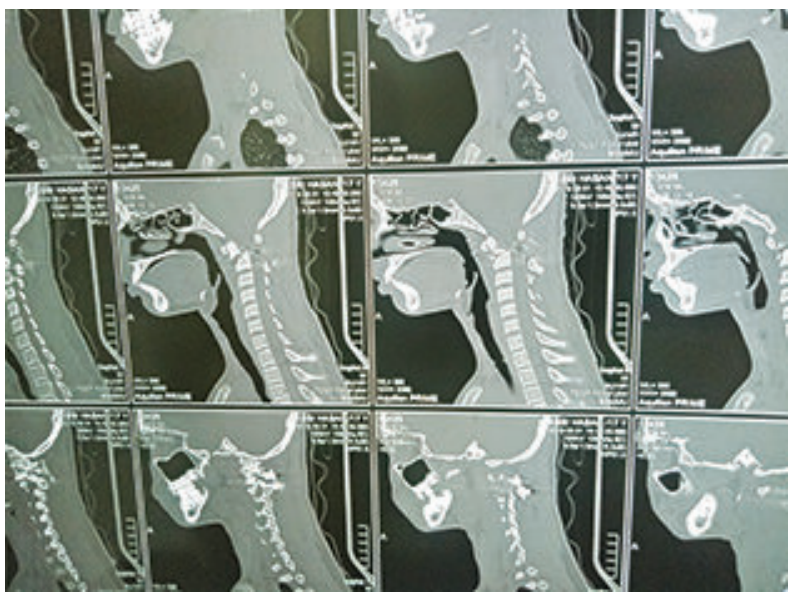

Fig.-7: CT scan of cervical spine with OS odontoidium 


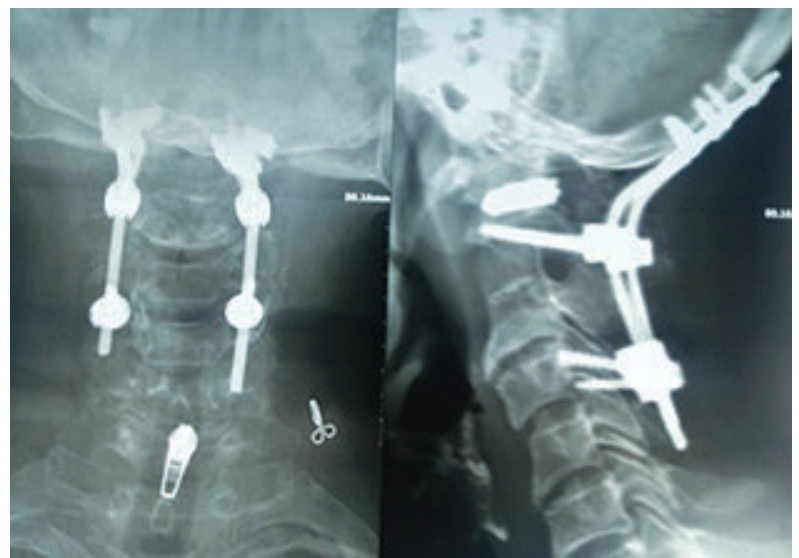

Fig.-8: Postoperative x-ray after occipito cervical fixation

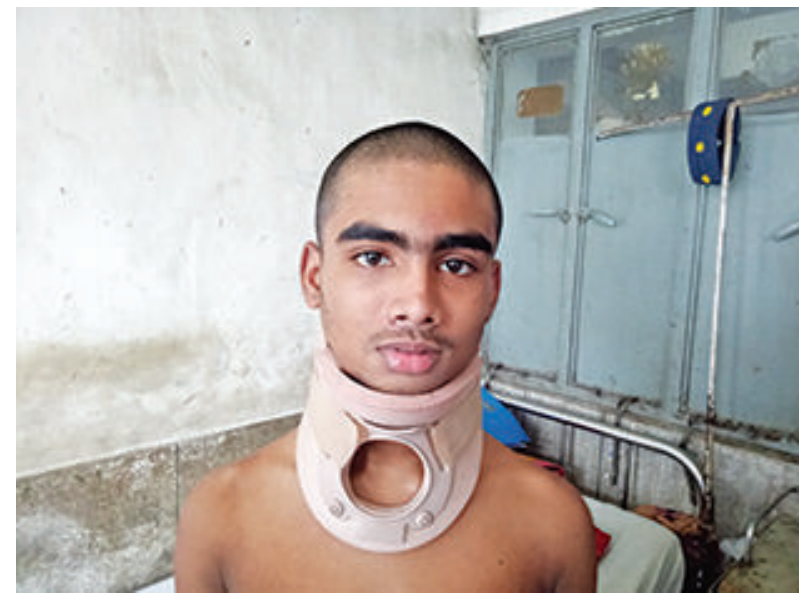

Fig.-9: Postoperative patient

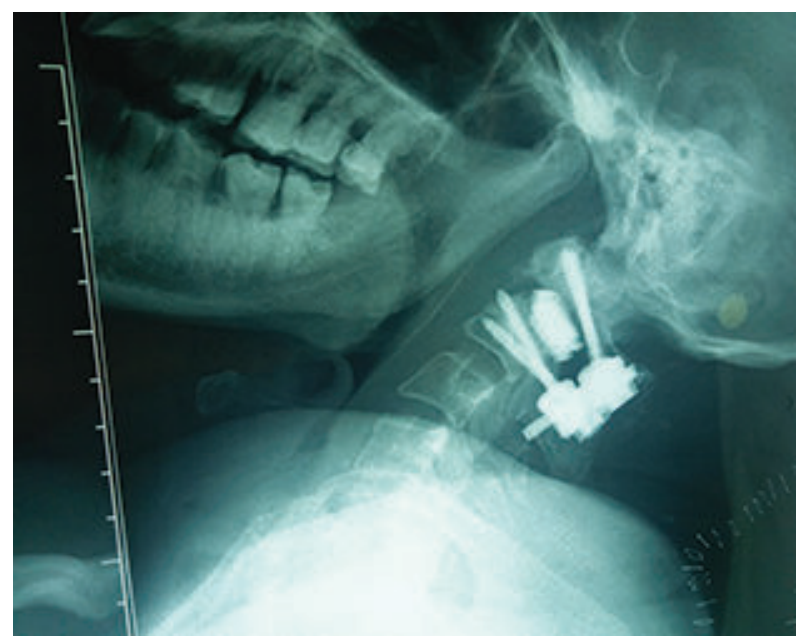

Fig.-10: Postoperative $x$-ray after fixation

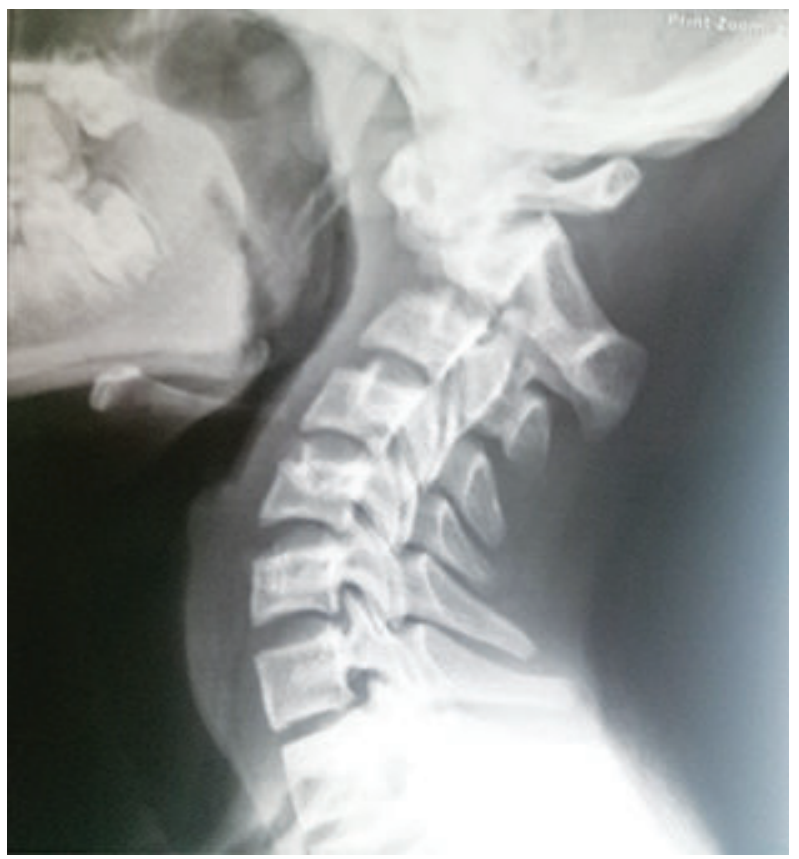

Fig.-11: Pre-operative $x$-ray with atlantoaxial dislocation

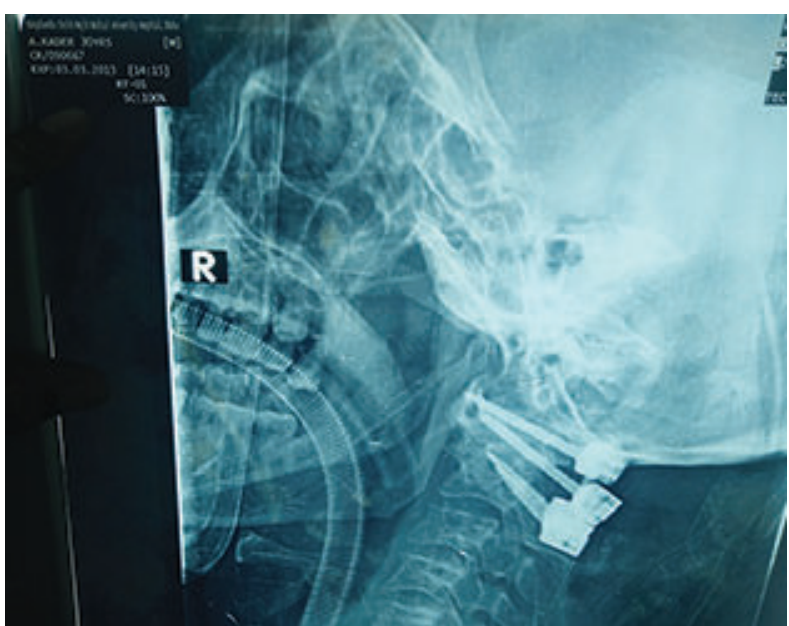

Fig.-12: Per-operative $x$-ray after fixation

\section{Discussion:}

The invasion to upper cervical lesions itself may contribute to this kyphotic alignment change because the semispinalis cervical muscle needs to be partially removed during surgery. In Atlanto axial sublaxtion surgery, great care should be taken regarding the $\mathrm{C} 1 /$ 2 angle and the invasion of the muscles attached to C2. In addition, postoperative therapy to prevent kyphotic changes is considered important.

In patients who received $\mathrm{C} 1 / 2$ fixation, higher preoperative $A D I$ and good reduction of $A D I$ were related to good surgical outcomes in high-ADI patients, anterior subluxation of $\mathrm{C} 1$, and instability at $\mathrm{C} 1 / 2$ are 
considered the main factors for neurological problems. Thus, a good reduction of the ADI is directly associated with decompression of the spinal cord and neurological recovery. However, in patients with a small $A D I$, other pathogens, such as periodontoid synovitis, may also cause the neurological impairment and thus the neurological recovery may not be as good as that in patients with a high preoperative ADI.

Spinal surgery in Atlanto axial sublaxtion patients has been considered challenging because most patients are elderly and have multiple medical problems.

A high incidence of surgical site infections is also an issue in spinal operations for Atlanto axial sublaxtion patients. The Atlanto axial sublaxtion patients in this study included a large number of patients who had a high risk of developing SSI, including patients with diabetes mellitus and collagen diseases such as RA and patients taking other immunosuppressants. In addition, risk for skin contamination is high in the upper cervical region. ${ }^{18}$

In this study, the rate of SSI was indeed high (10.00\%). In a previous study SSI rate was $6.66 \%{ }^{10}$. These results indicate that patients with Atlanto axial sublaxtion need a more careful risk assessment and risk management, especially those who undergo fixation surgery.

In present study after surgery neurological improvement rate is $83.33 \%$. But in a previous series following $\mathrm{C} 1 / 2$ fixation was $72.00 \% .^{10}$

In our series total death rate was $3.33 \%$. It was due to instrument failure. But in a previous history death rate was $00 .{ }^{10}$

The hardware failure rate was $1(3.33 \%)$ in the Atlanto axial sublaxtion patients in our series. In a previous series there was no instrument failure. ${ }^{10}$

The reoperation rate reached $2(6.66 \%)$ in the Atlanto axial sublaxtion patients in our series. One for hematoma \& another one for instrument failure. In a previous series re-operation rate was the same. ${ }^{10}$

\section{Conclusion:}

In our case series of surgically treated Atlanto axial sublaxtion, the $\mathrm{C} 1 / 2$ fixation technique exhibited effectiveness in terms of neurological recovery. For patients with high preoperative ADI, C1/2 fixation with reduction is generally recommended.

\section{Reference:}

1. Yang SY, Boniello AJ, Poorman CE, Chang AL, Wang S, Passias PG. A Review of the Diagnosis and Treatment of Atlantoaxial Dislocations. Global Spine Journal 2014;4 (3):197-207.
2. Wasserman BR,Moskovich R, Razi AE. Rheumatoid arthritis of the cervical spine-clinical considerations. Bull NYUHosp Jt Dis 2011;69(2):136-148.

3. Tulsi RS. Some specific anatomical features of the atlas and axis:dens, epitransverse process and articular facets. Aust N Z J Surg 1978;48(5):570-574.

4. Venkatesan M, Bhatt R, Newey ML. Traumatic atlantoaxial rotatory subluxation in adults: a report of two cases and literature review. Injury 2012;43(7):1212-1215.

5. Hedequist D, Bekelis K, Emans J, Proctor MR. Single stage reduction and stabilization of basilar invagination after failed prior fusion surgery in childrenwith Down's syndrome. Spine 2010;35(4):E128-E133

6. Bouchaud-Chabot A, Lioté F. Cervical spine involvement in rheumatoid arthritis. A review. Joint Bone Spine 2002;69(2):141-154.

7. Passias PG, Wang S, Kozanek M, Wang S, Wang C. Relationship between the alignment of the occipitoaxial and subaxial cervical spine in patients with congenital atlantoxial dislocations. J Spinal Disord Tech 2013;26(1):15-21.

8. Panda S, Ravishankar S, Nagaraja D. Bilateral vertebral artery dissection caused by atlantoaxial dislocation. J Assoc Physicians India 2010;58:187-189.

9. Reddy KR, Rao GS, Devi BI, Prasad PV, Ramesh VJ. Pulmonary function after surgery for congenital atlantoaxial dislocation: a comparison with surgery for compressive cervical myelopathy and craniotomy. J Neurosurg Anesthesiol 2009;21(3):196-201.

10. Yamada T, Yoshii T, Matsukura Y, Oyaizu T, Yuasa M, Hirai $\mathrm{T}$, Sakaki K, Inose H. Retrospective analysis of surgical outcomes for atlantoaxial subluxation. Journal of Orthopaedic Surgery and Research 2019;14:1-8.

11. Kakutani K, Doita M, Yoshikawa M. C1 laminectomy for retro-odontoidpseudotumor without atlantoaxial subluxation: review of seven consecutive cases. Eur Spine J. 2013;22:1119-26.

12. Toyama $\mathrm{Y}$, Matsumoto $\mathrm{M}$, Chiba K. Realignment of postoperative cervical kyphosis in children by vertebral remodeling. Spine 1994;19:2565-70.

13. Yoshimoto $\mathrm{H}$, Ito $\mathrm{M}$, Abumi $\mathrm{K}$, et al. A retrospective radiographic analysis of subaxial sagittal alignment after posterior C1-C2 fusion. Spine 2004;29:175-81.

14. Ishii K, Matsumoto M, Takahashi $Y$, et al. Risk factors for development of subaxial subluxations following atlantoaxial arthrodesis for atlantoaxial subluxations in rheumatoid arthritis. Spine 2010;35:1551-5.

15. lizuka $\mathrm{H}$, lizuka $\mathrm{Y}$, Kobayashi $\mathrm{R}$. Effect of a reduction of the atlanto-axial angle on the cranio-cervical and subaxial angles following atlanto-axial arthrodesis in rheumatoid arthritis. Eur Spine J. 2013;22:1137-41.

16. lizuka $\mathrm{H}$, lizuka $\mathrm{Y}$, Mieda $\mathrm{T}$, et al. A retrospective analysis of subaxial subluxation after atlanto-axial arthrodesis in patients with rheumatoid arthritis based on annual radiographs obtained for 5 years. Clin Spine Surg. 2017;30:E598-602.

17. Kato Y, Itoh T, Kanaya K, Kubota M, Ito S. Relation between atlantoaxial (C1/2) and cervical alignment (C2-C7) angles with Magerl and Brooks techniques for atlantoaxial subluxation in rheumatoid arthritis. J Orthop Sci. 2006;11:347-52.

18. Yamada T, Yoshii T, Egawa S. Drain tip culture is not prognostic for surgical site infection in spinal surgery under prophylactic use of antibiotics. Spine 2016;41:1179-84. 